\title{
Catel-Manzke syndrome
}

INSERM

\section{Source}

INSERM. (1999). Orphanet: an online rare disease and orphan drug data base. CatelManzke syndrome. ORPHA:1388

Catel-Manzke syndrome is a rare bone disease characterized by bilateral hyperphalangy and clinodactyly of the index finger typically in association with Pierre Robin sequence (see this term) comprising microg nathia, cleft palate and glossoptosis. 